Acta Crystallographica Section E

Structure Reports

Online

ISSN 1600-5368

\section{H. S. Yathirajan, ${ }^{a}$ Anil N.} Mayekar, ${ }^{\text {a }}$ B.K. Sarojini, ${ }^{\text {b }}$ B. Narayana ${ }^{c}$ and Michael Bolte ${ }^{d_{*}}$

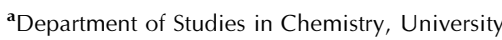
of Mysore, Manasagangotri, Mysore 570 006, India, 'b Department of Chemistry, P. A. College of Engineering, Nadupadavu, Mangalore 574 153, India, ' Department of Chemistry, Mangalore University, Mangalagangotri 574 199, India, and Institut für Anorganische Chemie, J. W. Goethe-Universität Frankfurt, Max-von-Laue-Strasse 7, 60438 Frankfurt/Main, Germany

Correspondence e-mail:

bolte@chemie.uni-frankfurt.de

\author{
Key indicators \\ Single-crystal X-ray study \\ $T=173 \mathrm{~K}$ \\ Mean $\sigma(\mathrm{C}-\mathrm{C})=0.003 \AA$ \\ $R$ factor $=0.040$ \\ $w R$ factor $=0.097$ \\ Data-to-parameter ratio $=7.6$
}

For details of how these key indicators were automatically derived from the article, see http://journals.iucr.org/e.

\title{
(2E)-3-(6-Methoxy-2-naphthyl)-1-phenyl- prop-2-en-1-one
}

The geometric parameters of the title compound, $\mathrm{C}_{20} \mathrm{H}_{16} \mathrm{O}_{2}$, are in the usual ranges. The central double bond is trans configured. Its two $\mathrm{C}$ atoms are slightly twisted out of the naphthyl plane. The dihedral angle between the aromatic groups is $14.09(8)^{\circ}$.

\section{Comment}

Reviews on the bioactivities of varieties of chalcones are given by Dimmock et al. (1999) and Go et al. (2005). Recently, it has been noted that, among many organic compounds reported for their second harmonic generation, chalcone derivatives are known for their excellent blue light transmittance and good crystallizability (Fichou et al., 1988; Goto et al., 1991; Uchida et al., 1998; Zhao et al., 2000; Sarojini et al., 2006). The crystal structures of 3-(4-chlorophenyl)-1-(2-naphthyl)prop-2-enone (Shanmuga Sundara Raj et al., 1997), 1-(2-naphthalenyl)-3-(3nitrophenyl)-2-propen-1-one (Shanmuga Sundara Raj et al., 1998), 3-(6-methoxy-2-naphthyl)-1-(2-naphthyl)prop-2-en-1one (Yathirajan, Sarojini, Bindya et al., 2006) and 3-(6-methoxy-2-naphthyl)-1-(2-thienyl)prop-2-en-1-one (Yathirajan, Narayana et al., 2006) have been reported. The crystal structures of 1-(2,4-dichloro-5-fluorophenyl)-3-(3,4-dimethoxyphenyl)prop-2-en-1-one (Yathirajan, Sarojini, Narayana et al., 2006) and (2E)-1-(2,4-dichlorophenyl)-3-[4-(methylsulfanyl) phenyl]prop-2-en-1-one (Butcher et al., 2007) have also been reported. In continuation of our broad programme on chalcones, the present paper reports the crystal structure of a newly synthesized chalcone.<smiles>COc1ccc2cc(/C=C/C(=O)c3ccccc3)ccc2c1</smiles>

(I)

A perspective view of the title compound, (I), is shown in Fig. 1. Bond lengths and angles can be regarded as normal [Cambridge Crystallographic Database, Version 5.28, November 2006 (Allen, 2002); Mogul Version 1.1 (Bruno et al., 2004)]. The carbonyl group is twisted by $21.0(3)^{\circ}$ out of the plane of the phenyl ring. The torsion angle between the carbonyl group and the $\mathrm{C}$ atoms of the double bond is $-15.9(4)^{\circ}$. The torsion angle between the the $\mathrm{C}$ atoms of the double bond and the adjacent naphthyl residue $(\mathrm{C} 2-\mathrm{C} 3-$ $\mathrm{C} 21-\mathrm{C} 30)$ is $-10.4(3)^{\circ}$. The two aromatic residues are not coplanar [dihedral angle $14.9(8)^{\circ}$ ].

There are non-conventional hydrogen bonds of the type $\mathrm{C}-\mathrm{H} \cdots \mathrm{O}$ in the structure that link the molecules into chains
Received 22 January 2007 Accepted 26 January 2007 
lying along the $b$ axis. In addition to these intermolecular interactions, intramolecular interactions $\mathrm{C} 3-\mathrm{H} 3 \cdots \mathrm{O} 1$ are also present (Table 1).

\section{Experimental}

$5 \mathrm{ml}$ of $40 \% \mathrm{KOH}$ solution was added to a thoroughly stirred solution of acetophenone $(1.2 \mathrm{~g}, 0.01 \mathrm{~mol})$ and 6-methoxy-2-napthaldehyde $(1.86 \mathrm{~g}, 0.01 \mathrm{~mol})$ in $25 \mathrm{ml}$ of methanol. The mixture was stirred overnight and filtered. The solid obtained was recrystallized from acetone-toluene (1:1) mixture (m.p. 421-423 K). Analysis for $\mathrm{C}_{20} \mathrm{H}_{16} \mathrm{O}_{2}$ found (calculated): C 83.18 (83.31), H 5.50 (5.59)\%.

\section{Crystal data}

$\mathrm{C}_{20} \mathrm{H}_{16} \mathrm{O}_{2}$

$M_{r}=288.33$

Orthorhombic, $P c a 2_{1}$

$a=14.5275$ (17) $\AA$

$b=17.0930(15) \AA$

$c=5.9950(5) \AA$

$V=1488.7(3) \AA^{3}$

$$
\begin{aligned}
& Z=4 \\
& D_{x}=1.286 \mathrm{Mg} \mathrm{m}^{-3} \\
& \text { Mo } K \alpha \text { radiation }^{-1} \\
& \mu=0.08 \mathrm{~mm}^{-1} \\
& T=173(2) \mathrm{K} \\
& \text { Thick plate, light yellow } \\
& 0.27 \times 0.24 \times 0.13 \mathrm{~mm}
\end{aligned}
$$

\section{Data collection}

Stoe IPDS II two-circle

diffractometer

$\omega$ scans

Absorption correction: none

7578 measured reflections

$$
\begin{aligned}
& 1535 \text { independent reflections } \\
& 1367 \text { reflections with } I>2 \sigma(I) \\
& R_{\text {int }}=0.089
\end{aligned}
$$$$
\theta_{\max }=25.6^{\circ}
$$

\section{Refinement}

Refinement on $F^{2}$

$R\left[F^{2}>2 \sigma\left(F^{2}\right)\right]=0.040$

$w R\left(F^{2}\right)=0.097$

$S=1.03$

1535 reflections

201 parameters

$\mathrm{H}$-atom parameters constrained

$$
\begin{aligned}
& w=1 /\left[\sigma^{2}\left(F_{\mathrm{o}}{ }^{2}\right)+(0.0648 P)^{2}\right] \\
& \text { where } P=\left(F_{\mathrm{o}}{ }^{2}+2 F_{\mathrm{c}}{ }^{2}\right) / 3 \\
& (\Delta / \sigma)_{\max }<0.001 \\
& \Delta \rho_{\max }=0.21 \mathrm{e} \AA^{-3} \\
& \Delta \rho_{\min }=-0.21 \mathrm{e} \AA^{-3} \\
& \text { Extinction correction: SHELXL97 } \\
& \text { Extinction coefficient: } 0.029(5)
\end{aligned}
$$

\section{Table 1}

Hydrogen-bond geometry $\left(\AA{ }^{\circ}{ }^{\circ}\right)$.

\begin{tabular}{lllll}
\hline$D-\mathrm{H} \cdots A$ & $D-\mathrm{H}$ & $\mathrm{H} \cdots A$ & $D \cdots A$ & $D-\mathrm{H} \cdots A$ \\
\hline $\mathrm{C} 3-\mathrm{H} 3 \cdots \mathrm{O} 1$ & 0.95 & 2.44 & $2.798(3)$ & 102 \\
$\mathrm{C} 14-\mathrm{H} 14 \cdots \mathrm{O} 2^{\mathrm{i}}$ & 0.95 & 2.53 & $3.462(3)$ & 168 \\
\hline
\end{tabular}

Symmetry code: (i) $x, y-1, z$.

In the absence of significant anomalous scatterers Friedel pairs were merged. $\mathrm{H}$ atoms were found in a difference map, but they were refined using a riding model with $\mathrm{C}-\mathrm{H}=0.95 \AA$ and $U_{\text {iso }}(\mathrm{H})=$ $1.2 U_{\text {eq }}(\mathrm{C})$ or with $\mathrm{C}-\mathrm{H}=0.98 \AA$ and $U_{\text {iso }}(\mathrm{H})=1.5 U_{\text {eq }}\left(\mathrm{C}_{\text {methyl }}\right)$. The methyl group was allowed to rotate but not to tip.

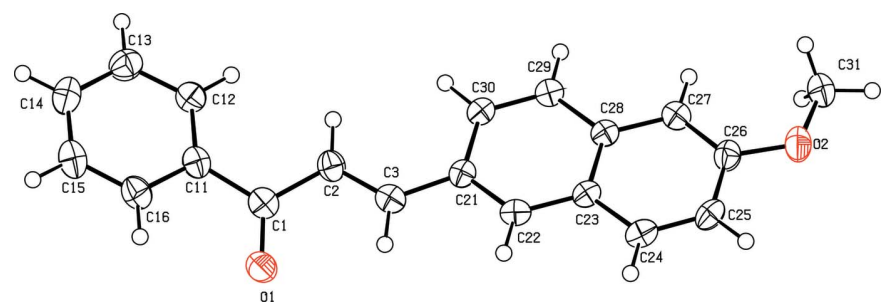

Figure 1

The molecular structure of the title compound with the atom numbering; displacement ellipsoids are at the $50 \%$ probability level.

Data collection: $X$-AREA (Stoe \& Cie, 2001); cell refinement: $X$-AREA; data reduction: $X$-AREA; program(s) used to solve structure: SHELXS97 (Sheldrick, 1997); program(s) used to refine structure: SHELXL97 (Sheldrick, 1997); molecular graphics: PLATON (Spek, 2003); software used to prepare material for publication: SHELXL97 and PLATON.

ANM thanks the University of Mysore for research facilities.

\section{References}

Allen, F. H. (2002). Acta Cryst. B58, 380-388.

Bruno, I. J., Cole, J. C., Kessler, M., Luo Jie, Motherwell, W. D. S., Purkis, L. H., Smith, B. R., Taylor, R., Cooper, R. I., Harris, S. E. \& Orpen, A. G. (2004). J. Chem. Inf. Comput. Sci. 44, 2133-2144.

Butcher, R. J., Yathirajan, H. S., Narayana, B., Mithun, A. \& Sarojini, B. K. (2007). Acta Cryst. E63, o30-032.

Dimmock, J. R., Elias, D. W., Beazely, M. A. \& Kandepu, N. M. (1999). Curr. Med. Chem. 6, 1125-1149.

Fichou, D., Watanabe, T., Takeda, T., Miyata, S., Goto, Y. \& Nakayama, M. (1988). Jpn. J. Appl. Phys. 27, 429-430.

Go, M. L., Wu, X. \& Liu, X. L. (2005). Curr. Med. Chem. 12, 483-499.

Goto, Y., Hayashi, A., Kimura, Y. \& Nakayama, M. (1991). J. Cryst. Growth, 108, 688-698.

Sarojini, B. K., Narayana, B., Ashalatha, B. V., Indira, J. \& Lobo, K. G. (2006). J. Cryst. Growth, 295, 54-59.

Shanmuga Sundara Raj, S., Ponnuswamy, M. N., Shanmugam, G. \& Nanjundan, S. (1997). Acta Cryst. C53, 917-918.

Shanmuga Sundara Raj, S., Ponnuswamy, M. N., Shanmugam, G. \& Nanjundan, S. (1998). Acta Cryst. C54, 541-542.

Sheldrick, G. M. (1997). SHELXS97 and SHELXL97. University of Göttingen, Germany.

Spek, A. L. (2003). J. Appl. Cryst. 36, 7-13.

Stoe \& Cie (2001). X-AREA. Stoe \& Cie, Darmstadt, Germany.

Uchida, T., Kozawa, K., Sakai, T., Aoki, M., Yoguchi, H., Abduryim, A. \& Watanabe, Y. (1998). Mol. Cryst. Liq. Cryst. 315, 135-140.

Yathirajan, H. S., Narayana, B., Ashalatha, B., Sarojini, B. K. \& Bolte, M. (2006). Acta Cryst. E62, o4440-o4441.

Yathirajan, H. S., Sarojini, B. K., Bindya, S., Narayana, B. \& Bolte, M. (2006). Acta Cryst. E62, o4046-o4047.

Yathirajan, H. S., Sarojini, B. K., Narayana, B., Bindya, S. \& Bolte, M. (2006). Acta Cryst. E62, o3631-o3632.

Zhao, B., Lu, W.-Q., Zhou, Z.-H. \& Wu, Y. (2000). J. Mater. Chem. 10, 15131517. 